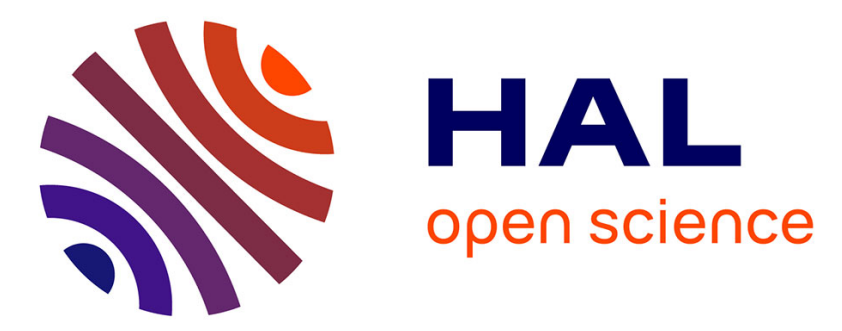

\title{
Buckling and spalling failure of alumina grown by oxidation on ODS FeCrAl alloys
}

Julien Sniezewski, Philippe Lours, Yannick Le Maoult

\section{To cite this version:}

Julien Sniezewski, Philippe Lours, Yannick Le Maoult. Buckling and spalling failure of alumina grown by oxidation on ODS FeCrAl alloys. Materials at High Temperatures, 2011, 28 (1), pp.17-20. 10.3184/096034011X12962385894289 . hal-01709490

\section{HAL Id: hal-01709490 \\ https://hal.science/hal-01709490}

Submitted on 25 Apr 2019

HAL is a multi-disciplinary open access archive for the deposit and dissemination of scientific research documents, whether they are published or not. The documents may come from teaching and research institutions in France or abroad, or from public or private research centers.
L'archive ouverte pluridisciplinaire HAL, est destinée au dépôt et à la diffusion de documents scientifiques de niveau recherche, publiés ou non, émanant des établissements d'enseignement et de recherche français ou étrangers, des laboratoires publics ou privés. 


\title{
Buckling and spalling failure of alumina grown by oxidation on ODS FeCrAl alloys
}

\author{
Julien Sniezewski, Philippe Lours* and Yannick Le Maoult \\ Université de Toulouse, Institut Clément Ader, Mines Albi,Campus Jarlard, \\ 81013 Albi, France \\ *E-mail: philippe.lours@mines-albi.fr
}

\begin{abstract}
In situ investigation of thermal shocks imposed to alumina grown on FeCrAl alloy at high temperature shows that interfacial buckling is the preferential route to spallation. Various parameters, either intrinsic or extrinsic to the substrate/oxide system, are analysed in terms of variation in interfacial fracture energies and propensity of alloy grains to wrinkle during high temperature exposure depending on their crystal orientation.
\end{abstract}

Keywords: in situ analysis, oxidation, buckling, spallation

\section{INTRODUCTION}

FeCrAl alloys protects from environmental attack by developing a dense, slowly growing and fairly adherent alumina scale over their surface when exposed to high temperature oxidation. Upon successive thermal shocks, inherent to their industrial use, this oxide layer may degrade through spallation, leaving the substrate unprotected and highly sensitive to oxidation. In this case, the cumulative cycles straightforwardly deplete the aluminium reservoir contained in the substrate alloy by successive re-oxidation and spallation, leading to the well-known break-away oxidation [1-3].

Although it is very interesting to characterise the material behaviour under conditions of cyclic oxidation which confer specific response to thermal loading, it is of utmost concern to investigate the mechanisms responsible for spallation as a result of cooling down to room temperature the material after a given holding period at high temperature. This has the virtue of providing information on the elementary sequences leading to surface spallation in relation to the microstructural features of both the alloy substrate and the thermally grown oxide (TGO).

The aim of the paper is to analyse quantitatively these elementary mechanisms using an innovative approach based on the real-time video-monitoring of the cooling sequences using various types of high resolution or high-speed CCD cameras.

\section{OXIDATION AND CONDITIONS FOR SPALLATION}

PM2000 alloy (Fe-Cr 19wt\%, Al $5.5 \mathrm{wt} \%$, Ti $0.5 \mathrm{wt} \%$, $\mathrm{Y}_{2} \mathrm{O}_{3} \quad 0.5 \mathrm{wt} \%$ ) was oxidised at various temperatures from $1050^{\circ} \mathrm{C}$ to $1400^{\circ} \mathrm{C}$ for time periods ranging between 168 hours and 819 hours. The alloy exhibits, in all case, parabolic oxidation kinetics and grows predominantly pure $\alpha$-alumina in agreement with literature [4].
At $1050^{\circ} \mathrm{C}$ and $1150^{\circ} \mathrm{C}$, the oxidation of the alloy over periods of 300 hours results in the growth of highly adherent TGO insensitive to spallation upon natural air-cooling. For higher oxidation temperatures, namely $1230^{\circ} \mathrm{C}, 1300^{\circ} \mathrm{C}$ and $1400^{\circ} \mathrm{C}$, the oxide scale tends to crack and spall as cooling of the material progresses. The extent of spallation is directly related to the temperature seen by the alloy. The higher the temperature, the more extensive is the spallation.

The spallation of the protective oxide scale is controlled by two interdependent parameters: the amplitude of the thermal shock $\left(\Delta \mathrm{T}=\mathrm{T}_{\text {oxidation }}-\mathrm{T}_{\text {ambient }}\right)$ and the thickness of the TGO. Note that returning to ambient temperature is not required to provoke spallation which may detrimentally develops from a threshold temperature, namely the critical temperature $\mathrm{T}_{\text {critical }}$, defining a critical temperature drop $\Delta \mathrm{T}_{\text {critical }}=\mathrm{T}_{\text {oxidation }}-\mathrm{T}_{\text {critical }}$. Coupled to the holding time at high temperature, the oxidation temperature $\mathrm{T}_{\text {oxidation }}$ determines the thickness of the TGO. From this, the conditions required for significant spallation to occur have been assessed based on TGO thickness considerations. The minimum oxidation holding time at $1300^{\circ} \mathrm{C}$, necessary to provoke spallation, has been experimentally determined. Subsequently, the corresponding critical thickness has been used to calculate the required holding times for all other oxidation temperatures investigated. This results in the building of a master curve shown in Figure 1 allowing to discriminate, for a given sets of parameters, namely the oxidation temperature versus the holding time at temperature, two domains defining respectively the conditions of scale spallation and scale adherence (top logarithmic time versus right oxidation temperature scales). For oxidation at $1300^{\circ} \mathrm{C}$, a holding time as low as 60 hours, leading to an oxide scale thickness of about $7.5 \mu \mathrm{m}$, is sufficient to initiate crack propagation and subsequent spallation of the TGO. In order to enhance further the mechanisms of surface degradation, holding times from 194 hours to 819 hours have been selected to investigate spallation mechanisms. This provides 


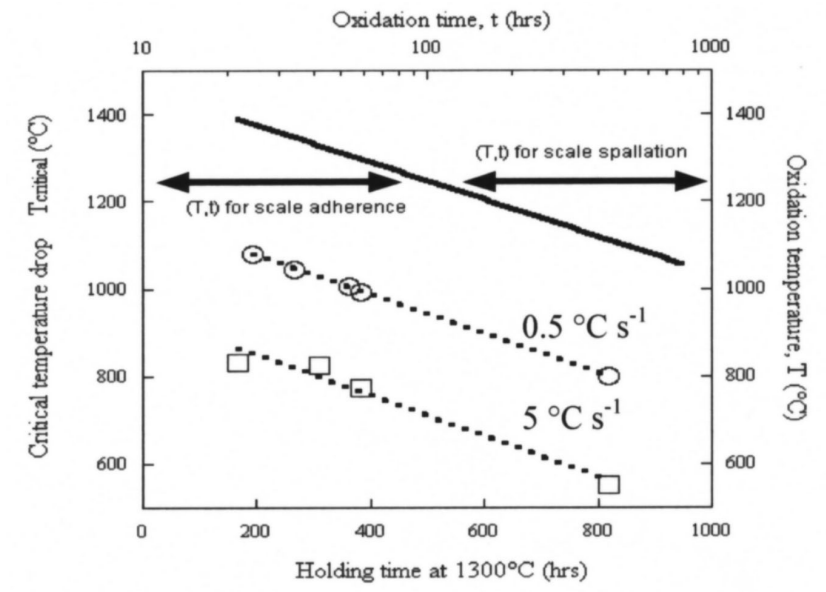

Figure 1 Master curve defining the couple "oxidation time $(\mathrm{t})$ and oxidation temperature ( $\mathrm{T}$ )" limiting the domain of scale adherence and scale spallation (full line top plot related to the top logarithmic $\mathrm{t}$ scale versus right $\mathrm{T}$ scale) and critical temperature drops for scale spallation following cooling at rates $0.5^{\circ} \mathrm{C} \mathrm{s}^{-1}$ and $5^{\circ} \mathrm{C} \mathrm{s}-1$ (central and bottom dotted line plots related to the bottom linear $\mathrm{t}$ scale versus left $\Delta \mathrm{T}_{\text {critical }}$ scale).

a satisfactory compromise between an oxidation temperature low enough to guarantee the metallurgical stability of the alloy substrate and a reasonably short duration of oxidation tests. Following oxidation, individual $6 \mathrm{~mm}$ thick, $2 \mathrm{~cm}$ square specimens are cooled down to room temperature, either in natural air or in contact with a high thermal conductivity aluminum specimen-holder immersed in liquid nitrogen, and the whole sequence is recorded using a camera capable of monitoring either seven images per second to derive the overall spallation kinetics or 88888 images to address the time scale of the spallation mechanisms. Individual photographs are extracted from the videorecording and treated using an image analysis software to estimate the critical temperature drop for spallation and the surface fraction of spall for each increment of time (and/or related decrement in temperature) as a function of (i) the microstructure of the alloy substrate, i.e. the crystal orientation of grains and (ii) the cooling rate.

\section{RESULTS AND DISCUSSION}

Critical temperatures for spallation are determined from a plot of the surface fraction spalled versus the temperature. An arbitrary threshold, corresponding to the spallation of one surface percent $(1 \%)$ of the oxide is chosen to estimate the required temperature drop to initiate TGO scale degradation. Depending on the holding time at $1300^{\circ} \mathrm{C}$, that is the oxide thickness, the critical temperature drop $\Delta \mathrm{T}_{\text {critical }}$ varies from $800^{\circ} \mathrm{C}$ (oxide thickness $36 \mu \mathrm{m}$ ) to $1080^{\circ} \mathrm{C}$ (oxide thickness $17 \mu \mathrm{m})$ for tests conducted in conditions of air-cooling (cooling rate: $0.5^{\circ} \mathrm{C} \mathrm{s}^{-1}$ ). Note that $\Delta \mathrm{T}_{\text {critical }}$ varies linearly as a function of the holding time at high temperature as shown in Figure 1 (bottom linear time versus left critical temperature drop scales). This suggests that the preferential mode of spallation likely corresponds to the buckling route [5] where the critical temperature drop is proportional to the square of the TGO thickness that is, for an alloy showing parabolic oxidation kinetics, proportional to the oxidation time. In this case, the interface between the oxide and the substrate exhibits a lower toughness that the oxide itself and is more prone to crack upon cooling. After cracking has developed at the interface, the oxide may buckle under the effect of transient stresses related to the mismatch in the coefficients of thermal expansion between the substrate alloy and the TGO. For more severe cooling (cooling rate: $5^{\circ} \mathrm{C}$ $\mathrm{s}^{-1}$ ), the critical temperature drop is much lower, for specimens either oxidised during 167 hours, 240 hours, 384 hours or $819 \mathrm{~h}$. In this later case, the ability of the bi-material to release the stress resulting from the thermal shock is drastically reduced. Indeed, the time interval during which the system can accommodate stresses through creep deformation is much shorter as the cooling rate increases. As a consequence, the degradation of the TGO, or more precisely of the interface between the substrate and the TGO in the case of the identified buckling mode, occurs at higher temperature but also at a higher rate. Note that the shift between the plots relative to the slow and the quick cooling is similar, i.e. $240^{\circ} \mathrm{C}$, for tests either conducted after 167 hours, 240 hours or 384 hours indicating that buckling is likely to operate for quick cooling as well. The temperature shift might be explained by a difference in the interfacial fracture energy being all the more low because the cooling rate is high [6].

The occurrence of buckling can be also assessed by a thorough analysis of the images extracted from video recordings. Figure 2 shows three successive views of a cooling sequence relative to a specimen oxidised 384 hours at $1300^{\circ} \mathrm{C}$ then cooled to room temperature at a cooling rate of $0.5^{\circ} \mathrm{C} \mathrm{s}^{-1}$. The initial state shows, at time $\mathrm{t}$, the presence of three buckles, which spontaneously form at $550^{\circ} \mathrm{C}$,

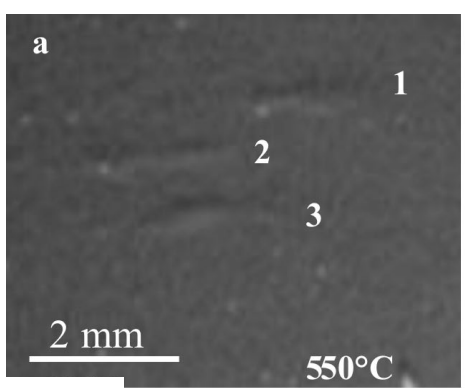

$\mathrm{t}$

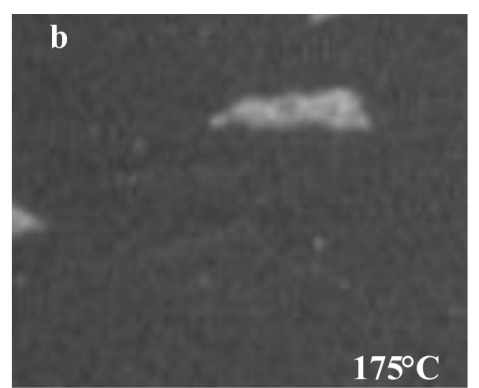

$\mathrm{t}+340 \mathrm{sec}$

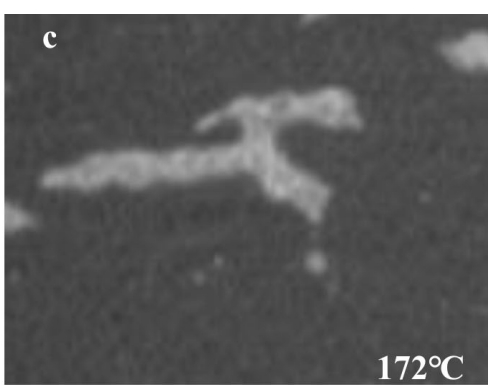

$\mathrm{t}+347 \mathrm{sec}$

Figure 2 Buckling and spallation of alumina grown on PM2000 substrate held 384 hours at $1300^{\circ} \mathrm{C}$ and air-cooled $\left(\operatorname{cooling}\right.$ rate $0.5^{\circ} \mathrm{C} \mathrm{s}{ }^{-1}$ ). 


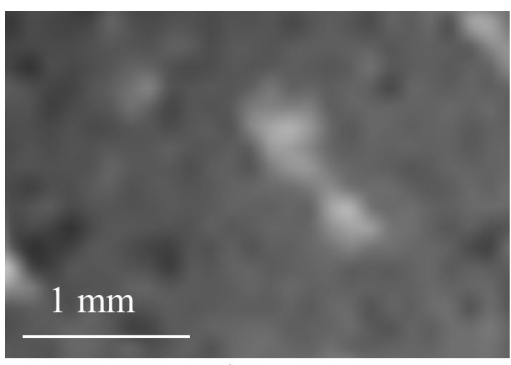

t

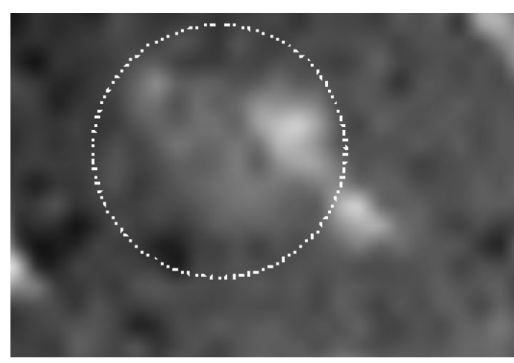

$\mathrm{t}+11 \mu \mathrm{s}$

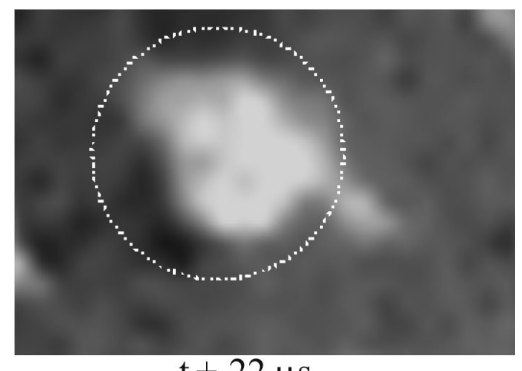

$\mathrm{t}+22 \mu \mathrm{s}$

Figure 3 Sequence of buckling and spallation of alumina grown on PM2000 substrate held 384 hours at $1300^{\circ} \mathrm{C}$, monitored using high speed camera.

labelled 1, 2 and 3, whose characteristic undulation is revealed by appropriate oblique lighting. Those buckles exhibit specific elongated morphologies in relation to the metallurgical grain structure of the creep resistant alloy substrate, particularly coarse and showing a large aspect ratio. Buckle 1 remains stable during the first 340 seconds of cooling, then spontaneously spalls off as the temperature reaches $175^{\circ} \mathrm{C}$. Further detachment of buckle 2 occurs 7 seconds later at $172^{\circ} \mathrm{C}$.

Generally speaking, buckles that nucleate within grains exhibit roughly circular isotropic shape as indicated in Figure 3, showing an analysis performed with a high speed camera able to monitor 88888 images per second. The analysis shows that the formation of the initial buckles, prior to full detachment from the substrate, occurs in less than one frame $(11 \mu \mathrm{s})$ as a result of a very high propagation rate of the interfacial crack, namely higher than $90 \mathrm{~m} \mathrm{~s}^{-1}$. In other words, it is practically impossible to determine the mechanism of interfacial crack propagation responsible for the buckle formation [3]. It shows that, following the buckle formation, no additional temperature drop is required to generate its instabilities responsible for its spallation. As a consequence, the critical temperature drop necessary to provoke buckling spallation $\left(\Delta \mathrm{T}_{\mathrm{c}}\right)$ may be considered equal to the temperature drop to form a buckle $\left(\Delta \mathrm{T}_{\mathrm{b}}\right)$. Using the buckling model proposed by Evans [5], it can be written:

$\left.\Delta \mathrm{T}_{\mathrm{c}}=\frac{1}{\Delta \alpha} \cdot \frac{1.052 \cdot \xi^{4}}{\mathrm{R}^{4}}+\frac{1.041 \cdot \gamma_{\mathrm{F}}}{\mathrm{E}_{\mathrm{ox}} \cdot \xi}\right)^{1 / 2}=\frac{1.22}{\Delta \alpha \cdot\left(1-v_{\mathrm{ox}}^{2}\right)} \cdot\left(\frac{\xi}{\mathrm{R}}\right)^{2}$

and thus, $\mathrm{R}$, the critical buckle radius prior to spallation is:

$$
\mathrm{R}=\xi \cdot \sqrt{\frac{1.22}{\Delta \alpha \cdot \Delta \mathrm{T}_{\mathrm{c}} \cdot\left(1-v_{\mathrm{ox}}^{2}\right)}}
$$

From this, the interfacial fracture energy $\gamma_{\mathrm{F}}$ can be straightforwardly calculated:

$$
\left.\gamma_{\mathrm{F}}=\frac{\mathrm{E}_{\mathrm{Ox}} \cdot \xi}{1.041} \cdot\left(\Delta \alpha \cdot \Delta \mathrm{T}_{\mathrm{c}}\right)^{2} \frac{1.052 \cdot \xi^{4}}{\mathrm{R}^{4}}\right)
$$

where $\Delta \alpha$ is the difference in thermal expansion coefficient between the substrate and the TGO, $\xi$ is the TGO thickness, $\mathrm{E}_{\mathrm{ox}}$ is the Young modulus of the TGO and $\nu_{\mathrm{ox}}$ is the Poisson coefficient of the TGO.
For a $36 \mu \mathrm{m}$ thick oxide scale, grown after 819 hours exposure at $1300^{\circ} \mathrm{C}, \mathrm{R}$ varies from $610 \mu \mathrm{m}$ in the condition of slow cooling $\left(0.5^{\circ} \mathrm{C} \mathrm{s}^{-1}, \Delta \mathrm{T}_{\mathrm{c}}=800^{\circ} \mathrm{C}\right)$ resulting in an interfacial fracture energy $\gamma_{\mathrm{F}}$ of $112 \mathrm{~J} \mathrm{~m}^{-2}$ to $698 \mu \mathrm{m}$ in the condition of quick cooling $\left(5^{\circ} \mathrm{C} \mathrm{s}^{-1}, \Delta \mathrm{T}_{\mathrm{c}}=550^{\circ} \mathrm{C}\right)$ leading to an interfacial fracture energy $\gamma_{\mathrm{F}}$ of $66 \mathrm{~J} \mathrm{~m}^{-2}$.

As suggested by the shape of some buckles, the microstructure of the alloy substrate must play a significant role in the process of buckle formation. Namely, the grain boundaries, locally enhancing the stress intensity factor as a result of structural incompatibilities drastically reduce the adherence of the oxide, leading to preferential spallation particularly during the first stages of spallation [3]. In addition, the spallation kinetics may differ significantly from one grain to its neighbours. As a matter of fact, using grain boundaries as markers, image analysis allows to accurately discriminate the spallation occurring over the different grains of a same specimen. Typical sigmoidal spallation kinetics, displaying both the surface fraction spalled ( $\%$ ) and the gross mass loss per unit surface $(\Delta \mathrm{m} / \mathrm{S})$ derived from $\mathrm{f} \%$ and the oxide thickness versus the cooling time and the cooling temperature, are presented in Figure 4a for a specimen containing three grains over the whole surface. Grain labelled $(\triangle)$ heavily spalled $(f=75 \%)$ as compared to the two other grains ( $\square$ and $\bigcirc$ ), respectively less spalled up to $49 \%$ and $39 \%$.

Micrographs in Figure 4 show respectively the initial substrate prior to oxidation with an indication of the crystal orientation of the grains (normal direction) determined by electron back scattering diffraction (b), the overall figure of spallation (c) and a high magnification imaging of the interfacial zone between grains $(\triangle)$ and $(\square)$ (d). The highly pronounced propensity of grain $\triangle$ to spall upon cooling, shown in Figure 4b, may be satisfactorily explained considering the surface wrinkling (Figure 4c) that occurs following the lateral growth of the oxide scale that stores a certain amount of elastic strain energy. Wrinkling results from the deformation of the underlying substrate that provokes the corrugation of the TGO, which may lose adherence from the substrate, especially at the peaks of the undulation wave produced. Upon cooling, compression stresses, favouring the detachment of the oxide, likely initiate interfacial cracks that may develop throughout the oxide thickness resulting in enhanced spallation through mixed cohesive/adhesive ruptures. As previously reported in [7] the trend for wrinkling may be related to the crystal orientation of grains. Those (111) oriented grains, prone to 


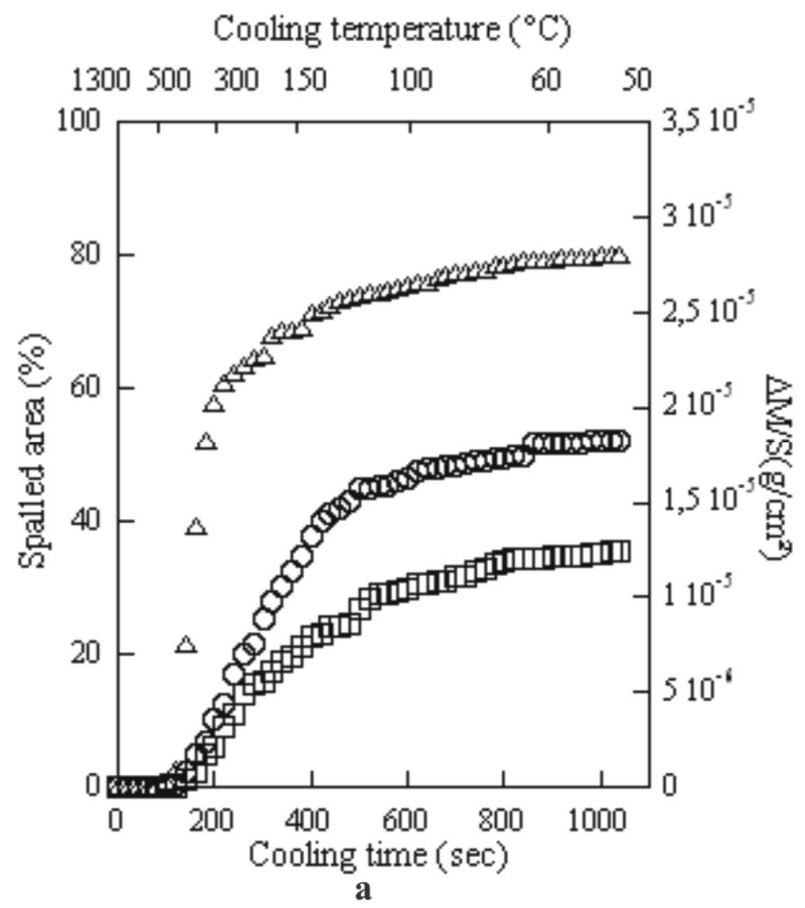

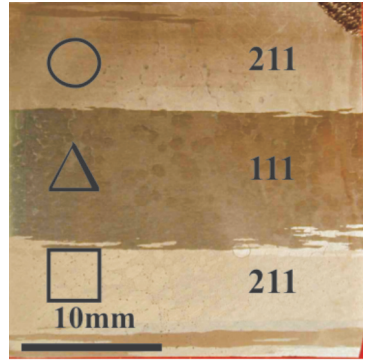

b

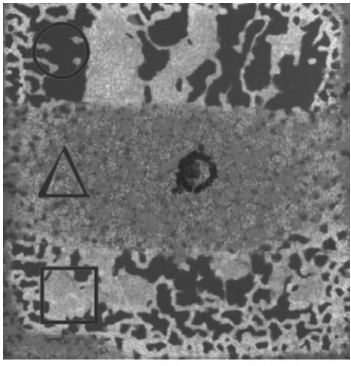

c

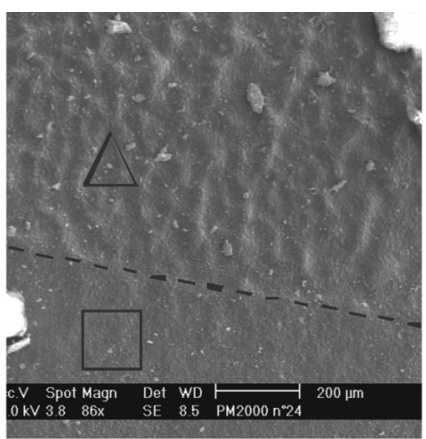

d

Figure 4 Spallation kinetics and cooling temperature (cooling rate $5^{\circ} \mathrm{C} \mathrm{s}^{-1}$ ) for three individual grains $[(\triangle)$ ), $(\square)$ and $(\bigcirc)$ ], after 384 hours oxidation at $1300^{\circ} \mathrm{C}$ (surface fraction spalled and related mass loss) (a) and substrate alloy microstructure with crystal orientation (b), overall spallation (c), and detail of central grain showing wrinkling (d).

produce wrinkling, release more easily the growth stress in the oxide scale through fast plastic creep deformation. It is suggested that additional parameters such as alumina grain size or grain aspect ratio may also play a significant role by modifying creep properties of the scale. Indeed, it might be considered that a larger density of alumina nuclei may form on (111) oriented grains resulting in a lower creep resistance. Conversely, (211) oriented grains may nucleate a lower density of alumina nuclei, leading to the growth of larger grains more prone to resist to creep.

\section{CONCLUSION}

An innovative in situ approach is used to investigate the microstructural drivers to spallation of alumina scales grown on FeCrAl ODS alloy, as well as to address the time scale of the mechanisms responsible for spallation. Both qualitative and quantitative analysis converge to indicate that scale spallation proceeds preferentially through the buckling route. It is shown that buckles form very quickly as monitoring in situ spallation using a high-speed camera does not allow to identify the sequence of interfacial crack initiation and propagation within the time frame of the high speed camera. Consequently, it is assumed that the critical temperature drop for buckle initiation is equal to the critical temperature drop for spallation. This allows the straightforward calculation of the fracture energy at the interface between the thermally grown oxide and the substrate responsible for the detachment of the TGO, as a function of the cooling rate after isothermal long term exposure at high temperature.

The buckle morphology, showing high aspect ratio, is directly related to the creep-resistant substrate microstruc- ture. In addition, the crystal orientation of the alloy grains has a strong influence on the extent of wrinkling, which in turn enhances spallation of the oxide scale. Extrinsic parameters such as the cooling rate of the oxidised alloy following various holding periods at high temperature, has a significant impact on the critical temperature drop to provoke spallation. The more pronounced propensity to spall upon higher cooling rate can be satisfactorily explained considering that, in this case, the time interval available to release stress through creep deformation is lower.

\section{ACKNOWLEDGEMENT}

The authors gratefully acknowledge Professor B. Pieraggi for his scientific support and fruitful discussions.

\section{REFERENCES}

[1] Merceron, G., Molins, R. and Strudel. J.L. (2000) Mater. High Temp., 17, 149-158.

[2] Nicholls, J.R. and Bennett, M.J. (2002) In: Quadakkers, Schütze W.J. and Nicholls, J.R. (eds), Life modelling of high temperature corrosion processes, pp. 3-14, MEFC Publication 34. Maney Publishing, London.

[3] Lours, P., Sniezewski, J., Le Maoult, Y. and Pieraggi, B. (2008) Mater. Sci. Eng. A, 480, 40-48.

[4] Lours, P., Alexis, J. and Bernhart, G. (1998) J. Mater. Sci. Lett., 17, 1089-1093.

[5] Evans, H.E. (1995) Int. Mater. Rev., 1(1), 1-40.

[6] Evans, H.E., Strawbridge, A., Carolan, R.A. and Ponton, C.B. (1997) Mater. Sci. Eng. A, 225, 1-8.

[7] Tolpygo, V.K. and Clarke, D.R. (1998) Acta Mater., 46, 14, 5153. 